\title{
Effect of magnet size on torque characteristic of three phase permanent magnet brushless DC motor
}

\begin{abstract}
This paper deals with a design of high torque brushless DC motor (BLDC). This motor is designed in new arrangement of the stator teeth and operated as three phase motor. This motor is developed to produce high torque performance motor that could be used as in-wheel motor for agriculture applications such as tractors. The basic structure and principle of the motor is described briefly. The simulation Finite Element Method (FEM) technique is used in order to analyze the performance of the motor including flux flow path and flux distribution. Various sizes of magnet had been varied for torque and motor efficiency analysis by using simulation and analytical method, respectively. This found that the maximum output torque is achieved when both length and width of magnet is at largest size. The result also signifies that the increment of torque will not determine the increases in the motor efficiency as well. In the end, this paper could be used as a further research for the future.
\end{abstract}

Keyword: High torque; Brushless DC motor 